University of Nebraska - Lincoln

DigitalCommons@University of Nebraska - Lincoln

USDA National Wildlife Research Center - Staff Publications
U.S. Department of Agriculture: Animal and Plant Health Inspection Service

March 2001

\title{
EFFECT OF PRIMARY AND SECONDARY REPELLENTS ON EUROPEAN STARLINGS: AN INITIAL ASSESSMENT
}

Roger W. Sayre

National Wildlife Research Center, U.S. Department of Agriculture, Animal and Plant Health Inspection Service

Larry Clark

USDA/APHIS/WS National Wildlife Research Center, larry.clark@aphis.usda.gov

Follow this and additional works at: https://digitalcommons.unl.edu/icwdm_usdanwrc

Part of the Environmental Sciences Commons

Sayre, Roger W. and Clark, Larry, "EFFECT OF PRIMARY AND SECONDARY REPELLENTS ON EUROPEAN STARLINGS: AN INITIAL ASSESSMENT" (2001). USDA National Wildlife Research Center - Staff Publications. 579.

https://digitalcommons.unl.edu/icwdm_usdanwrc/579

This Article is brought to you for free and open access by the U.S. Department of Agriculture: Animal and Plant Health Inspection Service at DigitalCommons@University of Nebraska - Lincoln. It has been accepted for inclusion in USDA National Wildlife Research Center - Staff Publications by an authorized administrator of DigitalCommons@University of Nebraska - Lincoln. 


\title{
EFFECT OF PRIMARY AND SECONDARY REPELLENTS ON EUROPEAN STARLINGS: AN INITIAL ASSESSMENT
}

ROGER W. SAYRE, 1, 2 National Wildlife Research Center, U.S. Department of Agriculture, Animal and Plant Health Inspection Service, 4101 West Laporte Avenue, Fort Collins, CO 80521, USA

LARRY CLARK, National Wildlife Research Center, U.S. Department of Agriculture, Animal and Plant Health Inspection Service, 4101 West Laporte Avenue, Fort Collins, CO 80521, USA

\begin{abstract}
Wildlife managers need chemical repellents that are effective at deterring damage by birds, but these repellents must be environmentally and toxicologically safe. The number of commercially available bird repellents has been reduced because of concerns about environmental safety. Currently, there are 2 categories of avian repellents. Chemicals that are reflexively avoided by birds because they irritate the peripheral chemical senses are referred to as primary repellents. Chemicals that cause gastrointestinal illness and learned avoidance of ancillary sensory cues that are paired with the illness are known as secondary repellents. Secondary repellents most often identified as the most effective avian repellents are derived from synthetic agrichemical pesticides and generally are regulated against because of their toxicity and concerns about the consequences of adding them to the environment. Primary repellents are usually derived from natural products and human food and flavor ingredients, and their use as bird repellents has been promoted as fulfilling the need for environmentally safe repellents. However, primary repellents are considered to be less potent than secondary repellents. We found that if the primary repellent, methyl anthranilate, was delivered enterically in European starlings (Sturnus vulgaris), we could achieve the same level of repellency as with the secondary repellent, methiocarb. Equal repellent effects for the 2 chemicals were found despite differences in their mode of action. Also, birds given an enteric delivery of the primary repellent methyl anthranilate showed fewer signs of behavioral distress (e.g., immobility and regurgitation) relative to those birds given the secondary repellent, methiocarb. By redirecting the site of action of a primary repellent, we have shown the feasibility to optimally combine the potency levels of secondary repellents with the biological and environmental safety attributes of primary repellents, without sacrificing efficacy. Primary repellents may be converted to secondary repellents via gastrointestinal delivery, thus potentially increasing efficacy and economic viability of these chemicals. Formulations that mask the irritating qualities of primary repellents are needed so that the chemical will be freely consumed by the target animal and exert its effect in the gastrointestinal tract.
\end{abstract}

JOURNAL OF WILDLIFE MANAGEMENT 65(3):461-469

Key words: food avoidance learning, methiocarb, methyl anthranilate, mimicry, repellents, starlings, Sturnus vulgaris.

The use of chemical repellents to reduce agricultural damage by birds has widespread applications (Mason and Clark 1987, 1992; Fagerstone and Schafer 1998). However, the number of products and active ingredients registered by the U.S. Environmental Protection Agency (EPA) for bird control has declined over the past 20 years (Clark 1998). In part, the reduction in the number of commercially available bird repellents reflects more stringent environmental standards required by the U.S. EPA (Fagerstone and Schafer 1998). The most significant effect of this regulatory change in standards has been loss of highly effective bird repellent products containing methiocarb (Dolbeer et al. 1994).

Methiocarb's effectiveness is due largely to its ability to produce severe, reversible illness after

\footnotetext{
1 E-mail: rsayre@peakpeak.com

2 Present address: Genesis Laboratories, Inc., P.O. Box 1150, Wellington, CO 80549, USA.
}

ingestion, which causes a bird to learn and avoid ancillary sensory cues-e.g., color, patterns, odors, and tastes-that are paired with the illness (Garcia et al. 1966, Mason and Reidinger 1983a, Conover 1984, Tobin 1985). This conditional avoidance depends on 4 critical features: (1) the unpleasant experience (i.e., the unconditional response [UCR], which in this case was the illness) attributed to the (2) toxicant, methiocarb (the unconditional stimulus [UCS]); (3) the paired ancillary sensory cues (the conditional stimuli [CS]); and (4) the learned avoidance (the conditional response [CR]). Chemical toxicants, such as methiocarb, that promote this type of classical conditioning (Pavlov 1906) are frequently referred to as secondary repellents (Rogers 1974). Generally, the magnitude of the conditional avoidance response is positively related to the magnitude of the illness (Domjan 1998). Unfortunately, many secondary repellents are derivatives of synthetic agricultural pesticides (Fagerstone and Schafer 1998). As a consequence, 
potent secondary repellents often have undesirable ancillary consequences, either directly in the form of physiological or metabolic side effects or side effects because of their degradation products (Dolbeer et al. 1994). Thus, there is a need to vigorously identify chemicals that are potent repellents, safe for animal use, and environmentally safe.

The use of primary repellents has been promoted as filling the need for effective, environmentally safe repellents (Mason and Clark 1992). The mode of action of primary repellents differs from secondary repellents in that primary repellents do not require learning to be effective because animals reflexively reject foods treated with the repellent chemical because of the chemical's unpalatable taste, odor, or irritating properties (Clark 1998). Often, primary repellents are derived from natural products used as human food and flavor ingredients because these chemicals have less toxic biological effects on the target species and more favorable environmental degradation characteristics than the synthetic agricultural pesticides typically adapted for use as secondary repellents.

Despite these positive attributes, primary repellents have not achieved the success of secondary repellents in the field. Because primary repellents are frequently more benign in their biological effects on the target organisms, the salience of the UCS is lower, hence primary repellents are often less effective than secondary repellents in promoting long-term avoidance responses (Domjan 1998). A further disadvantage of primary repellents is their tendency to degrade rapidly once placed in the environment (Aronov and Clark 1996). Primary repellents can be effective as feeding deterrents as long as the chemical persists on the treated substrate. However, once the repellent is removed, targeted animals typically return to cause damage (Conover 1984, Glahn et al. 1989).

The aforementioned field observations are consistent with laboratory studies demonstrating that primary repellents do not promote strong learned avoidance responses in birds (Clark 1996). One possible reason for the failure of birds to learn from their exposure to primary repellents is that they are better able to regulate their exposure to the repellent. Primary repellents are reflexively rejected because they frequently irritate nociceptors in the oral-nasal cavity. As such, the target animal never exposes itself to sufficient dosages that would cause severe gas- trointestinal illness. Thus, a primary repellent can be a sufficiently strong UCS to disrupt shortterm feeding behavior, but the unpalatability is not of sufficient strength or relevancy to promote learned avoidance of paired sensory cues (Domjan 1998). Despite these limitations, primary repellents remain of interest to wildlife managers because they are nonlethal and reasonably effective.

Modifications to primary repellents, changes in formulation, or changes in delivery tactics that would increase their salience to target animals so that long-term learned avoidance simulate secondary repellents are critical research areas in the development of nonlethal alternatives for wildlife management. One unexplored possibility is to determine whether a primary repellent can be formulated to mask its irritating qualities and thus bypass an animal's defensive peripheral sensory system. The formulation could be designed to disintegrate in the gastrointestinal system of the target animal, thus exposing enteric nociceptors to the repellent. The rationale for bypassing the oral cavity is twofold. First, the target animal would not be able to regulate the dosage of the repellent, thus it would expose itself to a higher dosage because its primary defensive sensory system would be bypassed. Second, a higher dosage of irritant delivered enterically would presumably represent a more salient UCS-UCR complex. For example, Pelchat et al. (1983) found that learned aversions were strongest if the UCS induced gastrointestinal illness, as compared with peripherally administered discomfort. In effect, this process would convert a primary repellent into the more effective secondary repellent simply through a reformulation process. If this delivery modification could be achieved, the question remains as to whether the converted repellent would be as effective an UCS as traditional secondary repellents derived from agricultural pesticides.

We tested the feasibility of this process by comparing the magnitude and duration of the learned avoidance response in starlings exposed to 2 bird repellents, methiocarb (a secondary repellent; Conover 1984) and methyl anthranilate (a primary repellent; Clark and Mason 1993).

\section{METHODS}

In lieu of encapsulating the repellents in these experiments we gavaged (i.e., delivered the repellent via intubation) birds to bypass the peripheral sensory system. This also ensured that 
the prescribed dosages were delivered directly to the gastrointestinal system.

\section{Study Subjects}

We decoy-trapped European starlings $(n=40)$ in Fort Collins, Colorado, during September 1998. Birds were individually housed and visually isolated in metal cages $(36 \times 23 \times 28 \mathrm{~cm}$; Animal Care Products, Bryan, Texas, USA). Each cage was equipped with a metal cage door $(23 \times 28$ $\mathrm{cm})$ constructed with wire bars $(0.32 \mathrm{~cm}$ diam $)$. The doors had 9 vertical bars (spaced $2.5 \mathrm{~cm}$ apart), and 5 horizontal bars (spaced $2.5-5.0 \mathrm{~cm}$ apart). A food cup and water bottle holder were attached to the cage door $5 \mathrm{~cm}$ above the wire mesh cage floor.

Birds were housed at $22^{\circ} \mathrm{C}$ and were maintained on a photoperiod that mimicked natural conditions during the experiments, which were conducted from November 1998 to April 1999. We provided starlings food (Purina Layena Checker) ad libitum in metal food cups $(8.3 \mathrm{~cm}$ diam) and unlimited access to water. To establish baseline food intake, we measured food consumption of each bird for $2 \mathrm{hr}$ (commencing $2 \mathrm{hr}$ after the onset of light) for 2 days prior to testing.

\section{Experiment 1}

We measured food consumption and quantified behavior of starlings throughout the 3 phases of the test paradigm: adaptation, training, and acquisition of learned avoidance. Our objectives were to determine whether a primary repellent (MA), delivered enterically, could promote learned avoidance of food paired with a colored and patterned target, and if so, how the effect size compared to a well-described secondary repellent, methiocarb.

Adaptation and Group Assignment.-After a 2-week adaptation period, we assigned birds to 1 of 4 groups ( $n=8 /$ group) based on food consumption. Birds were ranked according to consumption rates and assigned to groups so that each group had individuals with high, moderate, and low consumption rates so that mean group food intake was similar. Treatments administered during training were randomly assigned to the groups.

Training Day: Pre-gavage and Gavage.-Treatments included a null control (no gavage); a vehicle control of $2 \mathrm{ml} / \mathrm{kg}$ of propylene glycol (PG), which was used as a carrier for the repellents; a gavage with methiocarb $(2 \mathrm{mg} / \mathrm{kg})$, a secondary repellent diluted into PG $(2 \mathrm{ml} / \mathrm{kg})$; and methyl anthranilate $(20 \mathrm{mg} / \mathrm{kg})$, a primary repel- lent diluted into PG $(2 \mathrm{ml} / \mathrm{kg})$. Dosages of methiocarb and PG were based on reports by Mason and Reidinger $(1983 a, b)$. We conducted tests on a different set of starlings to determine that the MA dosage was sufficient to cause temporary irritation and delay of food consumption. Preliminary analyses of the methiocarb group indicated that the birds did not develop a learned aversion to the colored food cup. We added a second dosage level of $10 \mathrm{mg} / \mathrm{kg}$ ( $n=8$ naive starlings) to evaluate the effect on learning when the dosage of the UCS (methiocarb) is increased. These birds underwent the same acclimation, handling, and conditioning procedures as the other birds.

Approximately $16 \mathrm{hr}$ prior to administration of the gavage, we replaced the standard wire cage doors with plexiglass doors $(0.64 \mathrm{~cm}$ thick $)$. We installed the plexiglass doors to enhance videotaping and analysis. The placement of cup and water bottles on these doors was identical to the wire cage doors.

On the day of training, $2 \mathrm{hr}$ after the onset of light, we replaced the standard metal food cup with a cup with orange and black vertical stripes (CS). We chose the orange and black color pattern because Mason (1987) and Mason and Reidinger (1982) reported that vertical orange and black stripes were the most effective in learning trials with birds. Each cup contained $30 \mathrm{~g}$ of standard food. After $2 \mathrm{hr}$ of exposure to the food paired with the CS, we removed the cup and immediately took the test bird from its cage and gavaged it with repellent or PG (UCS-). The null control birds were handled, but not gavaged. We held each bird for $1 \mathrm{~min}$ after gavage to prevent regurgitation, and then returned the bird to its cage with $30 \mathrm{~g}$ of food in a plain metal food cup $\left(\mathrm{CS}^{\circ}\right)$.

Training Day: Post-gavage.-We measured food intake from the plain metal food cup $\left(\mathrm{CS}^{\circ}\right)$ for $2 \mathrm{hr}$ post-gavage. We also videotaped each bird during the first $2 \mathrm{hr}$ after gavage so we could quantify behavioral responses to the different treatments. Noldus Video Pro 4.0 (Noldus Information Technology, Wageningen, The Netherlands) was used as an aid to observe the videotapes. We conducted continuous focal observations (Martin and Bateson 1993) and developed an ethogram based on preliminary viewing of tapes. We trained observers to analyze the videotapes, but they did not know which treatment the bird in each tape had received.

The ethogram consisted of 4 behavioral states: moving, standing, feeding, and lying (sternal recumbent). The standing category included 4 
behavioral modifiers: preening, bill agape (indicating irritation), drooping (bird was immobilized and head/body angle was below a horizontal plane), and other (to denote all other standing). Each of the states and modifiers were exclusive (i.e., we could not record more than 1 state at the same time). Activity budgets were based on the duration of behavioral states and modifiers. The ethogram also included events, which were instantaneous behavioral occurrences that could take place during any state or modifier. Events included eating, dropping food, and drinking. In addition, our ethogram included irritation behaviors, which were categorized as head shakes, coughs, and regurgitation. Events were not included in the activity budget because they were instantaneous. However, the frequency and latency of events were included in the analyses.

We grouped activities into 5 categories: moving, standing alert, feeding, irritation (standing with bill agape), and immobilized (body posture drooping or sternal recumbent). Because some birds did not feed or drink during the 2-hr observation period, the latency to feeding and drinking data were evaluated 2 ways: with nonresponsive birds excluded from the analysis and with a latency value of $7,200 \mathrm{sec}$, the duration of the observation. We chose to analyze these data this way because nonresponsiveness of birds might be considered a behavioral outcome independent of the test. Likewise, the effect of the UCS may have caused the birds to avoid feeding or drinking altogether, hence the assignment of the 7,200 sec latency period.

2-Choice Learning Test.-On the day immediately following training, and $2 \mathrm{hr}$ after light onset, we conducted a 2-choice feeding test to determine whether a learned avoidance to food contained in an orange and black vertically striped food cup (UCS-) was acquired. Birds were simultaneously presented with the UCS ${ }^{-}$and food contained in a noncolored metal cup $\left(\mathrm{UCS}^{\circ}\right)$, and consumption from both cups was recorded at 2-hr intervals during the test period. Each cup contained $30 \mathrm{~g}$ of food. The position of the cup (left or right) was determined randomly. After $2 \mathrm{hr}$, we measured food intake from each cup. We determined preference ratios by dividing consumption from the colored cup by consumption from both cups combined, with a score of 1 indicating complete preference for the UCS, a score of 0 indicating complete avoidance of the $\mathrm{UCS}^{-}$, and a score of 0.5 indicating indifference to the UCS-
Due to small sample sizes we decided to forego the use of standard statistics (i.e., ANOVA) to evaluate our hypotheses. We calculated the $\bar{x}$ and SE for each treatment and used visual comparison of the control group against the respective treatment groups (Sokal and Rohlf 1984).

\section{Experiment 2}

From Experiment 1 there was evidence that the plexiglass cage door, used to enhance videotaping and analysis, interfered with the acquisition of food aversion, via a phenomenon called concurrent interference (Sayre and Clark 2001). Therefore, we repeated the above experiment, but without the distracting conditional visual cue of the clear plexiglass door. We retained the original door to the cage and repeated the experiment as described above. Exceptions to the test procedure were as follows. Starlings used in the experiment were used in Experiment 1. However, none of the birds previously used were assigned to a similar treatment category. Moreover, to minimize any effect of carryover learning, we waited $\geq 31$ days before retesting any bird $(\bar{x}=70.7$ days, $\mathrm{SE}=7.7$, range $=31-131, n=15)$. Mason et al. (1984) reported that learned avoidance lasted 10-12 days following treatment with methiocarb, and we believe that the time between experiments was sufficient to minimize possible bias.

We assigned birds to 1 of 3 treatment groups ( $n=$ 5 each). Treatments included vehicle control of PG $(2 \mathrm{ml} / \mathrm{kg}), \mathrm{MA}(20 \mathrm{mg} / \mathrm{kg})$, and methiocarb $(2 \mathrm{mg} / \mathrm{kg})$. We did not include a null control because the vehicle and null controls did not differ in Experiment 1. Therefore, we determined that only a vehicle control was necessary to safeguard against nonspecific experimental effects. We used the same training and testing procedures as Experiment 1 with the following exceptions: (1) the standard metal cage doors remained on the cages instead of the clear plexiglass doors; (2) we measured food consumption only during the first $2 \mathrm{hr}$ post-gavage; and (3) we did not analyze behavioral data from the videotapes.

We visually compared mean food consumption of controls PG versus MA and methiocarb during the 2-hr post-gavage period. Twenty-four hours after gavage, we calculated the mean preference ratios from the 2-choice learning test by dividing consumption from the colored cup by consumption from both cups combined. We visually compared the means of the treatments with the vehicle control. 

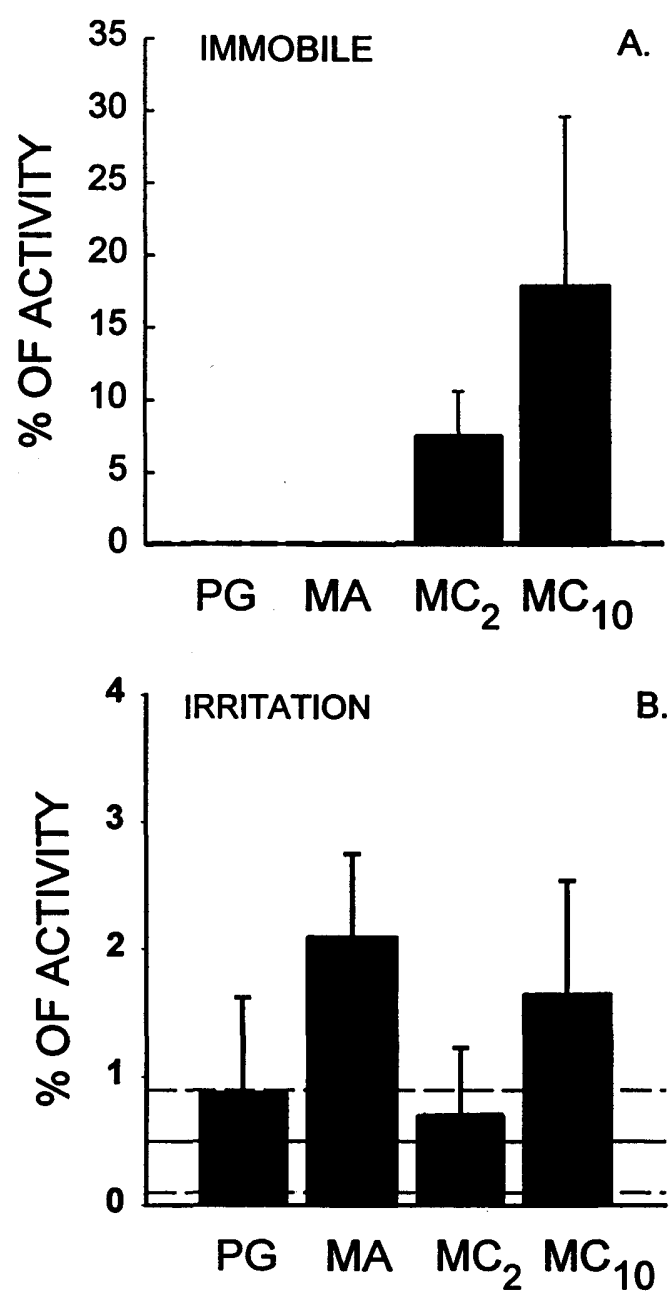

Fig. 1. A. Mean (+ SE) percentage of time starlings were immobilized by illness during the $2 \mathrm{hr}$ immediately following gavage, relative to the null control (horizontal solid line \pm SE [not visible with the scale shown in the figure]). B. Mean (+ SE) percentage of time starlings expressed behaviors defined as irritation responses during the $2 \mathrm{hr}$ immediately following gavage relative to the null control (horizontal solid line $\pm S E$ ). Treatment categories included the vehicle carrier, propylene glycol (PG); methyl anthranilate (MA); $2 \mathrm{mg} / \mathrm{kg}$ of methiocarb $\left(\mathrm{MC}_{2}\right)$; and $10 \mathrm{mg} / \mathrm{kg}$ of methiocarb $\left(\mathrm{MC}_{10}\right)$.

\section{RESULTS}

\section{Experiment 1}

Behavior of Starlings During Training.-Relative to the null control, methiocarb produced an illness-induced immobility in starlings, with a strong effect apparent at the level of $10 \mathrm{mg} / \mathrm{kg}$ (Fig. 1). Birds treated with $2 \mathrm{mg} / \mathrm{kg}$ methiocarb also exhibited some immobility after treatment, but the duration of immobility was $<50 \%$ as long as in the
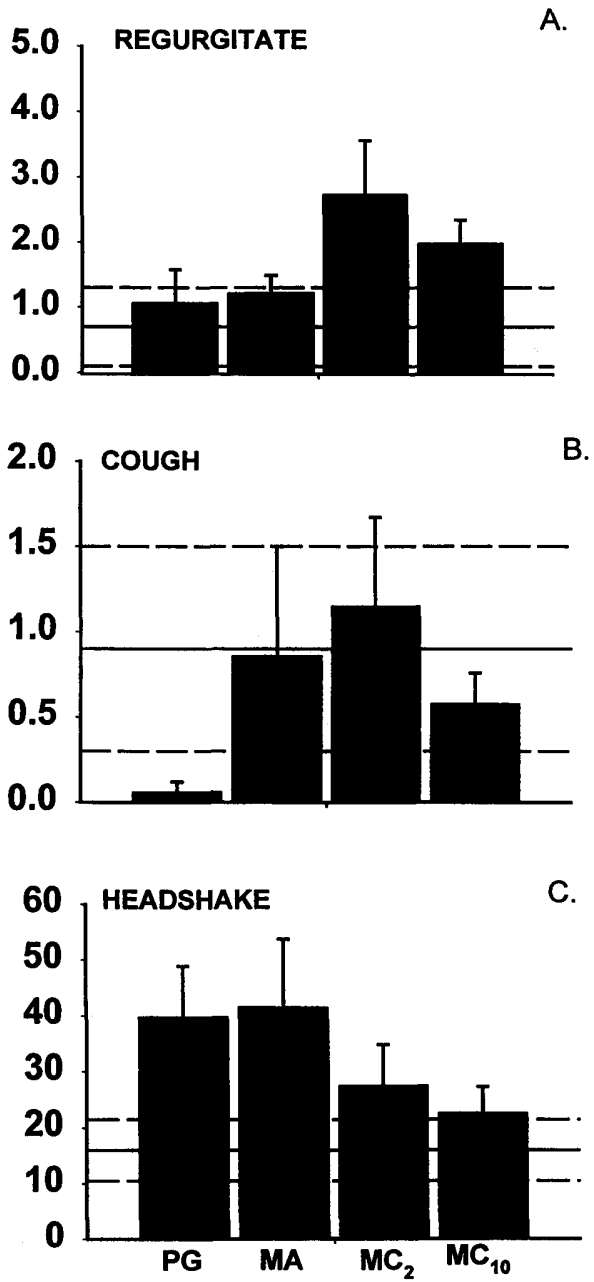

Fig. 2. A. Mean frequency ( $+\mathrm{SE})$ of regurgitation relative to the null control (solid horizontal line $\pm \mathrm{SE}$, the dotted horizontal lines) as a function of gavage treatment. B. Mean frequency (+SE) of coughing relative to the null control. $C$. Mean frequency $(+S E)$ of head shakes relative to the null control. Treatment categories included the vehicle carrier, propylene glycol (PG); methyl anthranilate (MA); $2 \mathrm{mg} / \mathrm{kg}$ of methiocarb $\left(\mathrm{MC}_{2}\right)$; and $10 \mathrm{mg} / \mathrm{kg}$ of methiocarb $\left(\mathrm{MC}_{10}\right)$.

birds treated with $10 \mathrm{mg} / \mathrm{kg}$ (Fig. 1). Methyl anthranilate produced the highest proportion of irritation reaction, with $>2 \times$ duration compared to controls, but starlings treated with MA showed no sign of immobility (Fig. 1). The vehicle control (PG) alone did not affect either behavior (Fig. 1).

Compared to controls, starlings gavaged with methiocarb at $2 \mathrm{mg} / \mathrm{kg}$ and $10 \mathrm{mg} / \mathrm{kg}$ were more likely to regurgitate following treatment (Fig. 2A). Gavage with methyl anthranilate and the vehicle 
control slightly increased the rate of regurgitation relative to the null control, but the frequency of regurgitations were about $50 \%$ as much as the 2 levels of methiocarb (Fig. 2A). Starlings showed a high degree of variability for coughing behavior and none of the gavage types appeared to influence this factor (Fig. 2B). Another measure of irritation, the rate of head shakes, indicated that all treatments resulted in an increase in head shakes, with the strongest effects observed among the vehicle control and with methyl anthranilate groups (Fig. 2C).

As evidenced by feeding and drinking behavior among the vehicle control group, starlings recovered from the effects of gavage within $300 \mathrm{sec}$ (Fig. 3). Any additional delay in the onset of feeding and drinking was presumed to be a relevant index of intestinal malaise resulting from the chemicals. The largest delay in the onset of feeding was seen for starlings gavaged with the higher dosage of methiocarb. Two of the starlings gavaged with the lower dosage of methiocarb failed

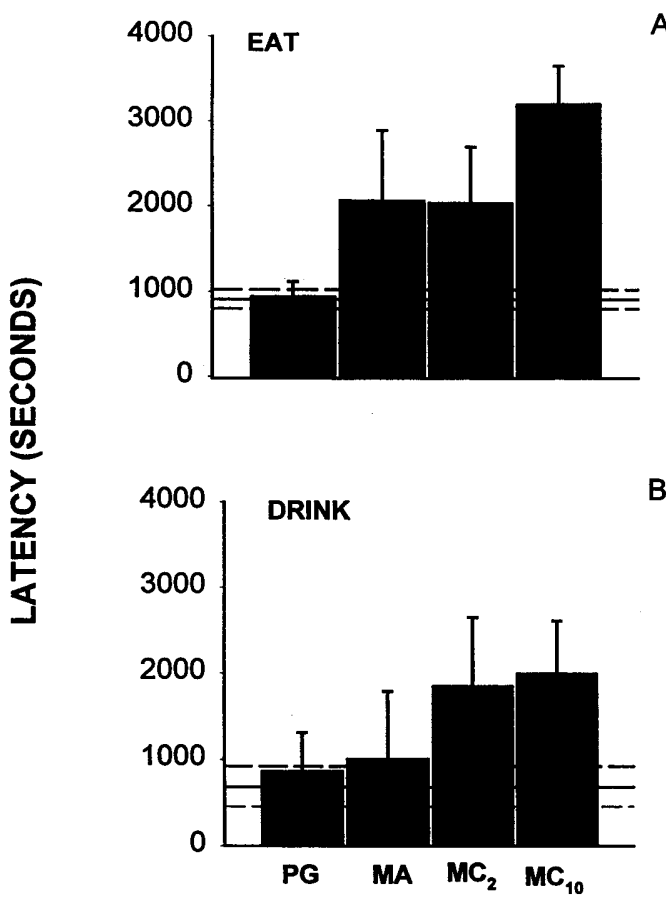

Fig. 3. A. Mean latency (sec) before starlings engaged in eating relative to the null control (mean $=$ the solid horizontal line $\pm \mathrm{SE}$, the dotted horizontal lines) as a function of gavage treatment. B. Mean latency (sec) before starlings engaged in drinking relative to the null control (mean $=$ the solid horizontal line \pm SE, the dotted horizontal lines) as a function gavage treatment. Treatment categories included the vehicle carrier, propylene glycol (PG); methyl anthranilate (MA); $2 \mathrm{mg} / \mathrm{kg}$ of methiocarb $\left(\mathrm{MC}_{2}\right)$; and $10 \mathrm{mg} / \mathrm{kg}$ of methiocarb $\left(\mathrm{MC}_{10}\right)$.

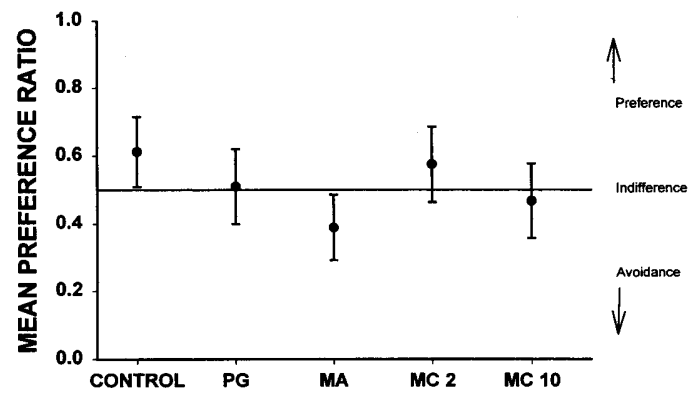

Fig. 4. Mean preference ratio of starlings during the 2-choice test in Experiment 1. Treatment categories included PG $(2 \mathrm{ml} / \mathrm{kg}$ propylene glycol); MA (20 mg/kg methyl anthranilate); methiocarb (2 mg/kg methiocarb); and methiocarb (10 mg/kg methiocarb). Circular $(\bullet)$ symbols represent the mean of the control and treatment groups; vertical lines and caps represent \pm 1 SE.

to feed during the 2-hr observation period. If these data were treated as missing, the group averaged a delay of just over 2,000 sec; however, if the nonfeeders were given a latency of 7,200 sec, the mean latency increased to over $3,500 \mathrm{sec}$. One bird from the methyl anthranilate cohort also did not eat during the trial. If data of the methyl anthranilate group is analyzed without this bird, the group also averaged 2,000 sec latency. When this nonfeeder was added to the analyses, the mean latency averaged just under $2,800 \mathrm{sec}$.

Starlings tended to resume drinking earlier than feeding (Fig. 3A,B). Starlings gavaged with both dosage levels of methiocarb resumed drinking within 2,100 sec after gavage. Starlings gavaged with methyl anthranilate and the vehicle control resumed drinking within $1,000 \mathrm{sec}$ of gavage. This was about the same delay in drinking behavior observed for the null controls after investigator-induced disturbance; i.e., entry and exit into the room to record data and perform experimental manipulations.

Learned Behavior of Starlings.-Despite showing clear signs of irritation or toxicosis, starlings failed to acquire a learned avoidance to the colored and patterned food cups (CS; Fig. 4). Subsequent experiments showed that the clear acrylic door introduced prior to the test acted as a distractor for the acquisition of learned avoidance behavior (Sayre and Clark 2001). Experiment 2 was undertaken to eliminate the concurrent interfering CS.

\section{Experiment 2}

As was the case in Experiment 1, gavage did not substantially affect food consumption on the day 


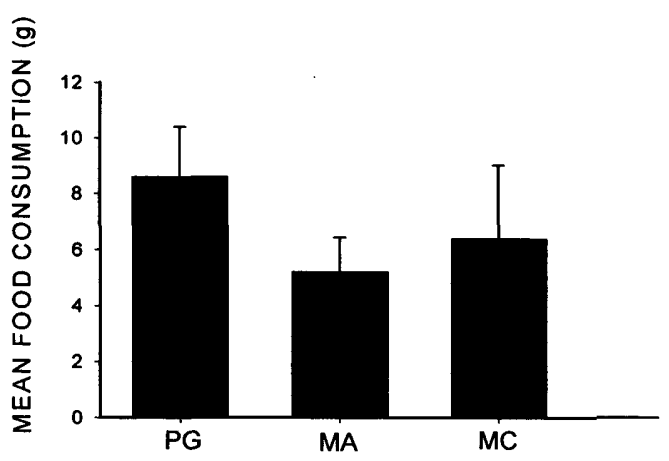

Fig. 5. Mean food consumption (g) of starlings during training phase of Experiment 2. Treatment categories included PG (2 $\mathrm{ml} / \mathrm{kg}$ propylene glycol); MA (20 mg/kg methyl anthranilate); and methiocarb $(2 \mathrm{mg} / \mathrm{kg}$ methiocarb). Circular $(\bullet)$ symbols represent the mean of the control and treatment groups; vertical lines and caps represent \pm 1 SE.

of training (Fig. 5). However, $24 \mathrm{hr}$ after training, birds showed strong evidence of learned avoidance. Compared to the vehicle control, as well as a hypothetical null preference ratio of 0.5 , starlings treated with methyl anthranilate and methiocarb displayed a tendency to avoid food in the colored cup (Fig. 6). The magnitude of effect among those treated with methyl anthranilate and methiocarb groups was relatively similar (Fig. 6).

\section{DISCUSSION}

The type of discomfort and distress produced by primary and secondary repellents differs in starlings. While this observation has been previously reported, this is the first study to quantify the types of distress behaviors and the magnitude of effect. Overall, enteric delivery of a primary repellent impacted activities related to physiological illness (i.e., immobility and gastrointestinal malaise) to a lesser degree than the secondary repellent. Yet under appropriate training conditions, the primary repellent was just as effective in producing conditioned aversions to visual cues as was the secondary repellent. Most importantly, the efficacy of the primary repellent was achieved with less impact to the target animal's well being relative to a secondary repellent.

The public demands more humane methods for the resolution of conflicts between humans and wildlife, but agricultural producers need effective deterrent strategies. In the past, the methods developed to meet both of these objectives at the same time appeared to be incompatible. The conversion of primary repellents to sec-

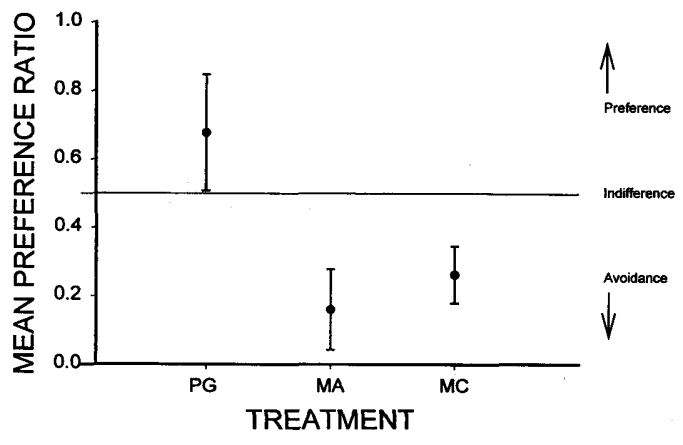

Fig. 6. Mean preference ratio of starlings during 2-choice test with standard cage door in Experiment 2. Treatment categories included PG (2 ml/kg propylene glycol); MA (20 mg/kg methyl anthranilate); and methiocarb (2 $\mathrm{mg} / \mathrm{kg}$ methiocarb). Circular $(\bullet)$ symbols represent the mean of the treatment groups; vertical lines and caps represent $\pm 1 \mathrm{SE}$.

ondary repellents demonstrates that fulfilling both objectives can be realized and represents a significant advance toward the goal of developing humane and effective wildlife repellents.

We also inadvertently demonstrated a welldescribed pitfall for studies on conditional avoidance learning; i.e., the concepts of concurrent interference and paired relevance of cues. In our case, placing a new door onto the cage to facilitate videorecording of behavior prior to the onset of the test effectively neutralized our ability to train starlings to avoid a visual target. Normally, a starling would be exposed to a distinctive visual cue during feeding (e.g., the orange and black stripes on the food cup), followed by the experience of chemically induced gastrointestinal illness. The next time the visual cue would be presented (e.g., $24 \mathrm{hr}$ later), the starling would avoid the food associated with the target. This process works because the visual target is closely paired with food and feeding behavior and is derivative of classic food aversion learning paradigms. However, when the new door was introduced in Experiment 1, the 2 visual cues were competing for the animal's attention. Apparently, the door was a more salient cue, but it did not have high relevance to food and feeding. The result was a failure of the bird to acquire a learned avoidance of the target cue and associated food. These results are important because they underscore the importance of the application method and, by implication, how effective a control strategy will work in the field. One foreseeable difficulty in using conditional food aversion paradigms might occur when they are used 
in combination with other deterrents (Nelms and Avery 1997). It is possible that employing multiple sensory cues may interfere with the visual cue paired with illness and food. Thus, what may seem to be a reasonable integrated approach to maximize repellency may actually render 1 of the techniques ineffective based on the principles of concurrent interference and paired relevance. These issues need to be addressed in a systematic and quantitative manner in field studies.

Little is known about how primary and secondary repellents compare in relation to extinction of learning, or how untreated birds would learn from observing illness in other birds. Mason (1987), Mason and Reidinger (1982), and Mason et al. (1984) demonstrated that birds will learn to avoid foods treated with secondary repellents when they observe repellent-induced toxicosis among other birds. However, the effectiveness of primary repellents on food aversion learning that is obtained vicariously is not known. Our laboratory is conducting research to evaluate the effectiveness of observational learning when demonstrator birds have been treated with primary repellents.

Formulation of primary repellents remains a critical wildlife deterrent issue (Clark 1998). The effectiveness of a repellent depends on a formulation that delivers the most salient cues to the birds. Thus, if feeding on crops is a major problem, then enteric delivery of a repellent would be more effective than topical application of a repellent that irritates the peripheral senses. Another problem is that a formulation should not counteract the effectiveness of the repellents. Likewise, formulation should not increase the toxicity of a primary repellent.

\section{MANAGEMENT IMPLICATIONS}

Converting primary repellents to secondary repellents offers several potential advantages over either type of chemical, if traditional delivery methodologies are used. Gastrointestinal delivery appears to increase the efficacy of primary repellents because gastrointestinal illness results in stronger avoidance learning (Pelchat et al. 1983). Moreover, if the flavor attributes of these compounds are masked by encapsulation, the effect would likely be greater because the animals would ingest more treated food and, by implication, gain additional exposure to more of the irritating chemical. If birds eat more treated food, then learned avoidance for the visual cue would increase because the strength of the unconditional stimulus would increase (Domjan 1998). An increased dose of repellent would result in longer avoidance of treated foods and less sampling behavior by birds, thus requiring use of less repellent because only a portion of the foods would require treatment.

Second, the economic feasibility of primary repellents could be improved by converting them to secondary repellents, especially if the principles of Batesian mimicry are used (Mason and Reidinger 1983b; Conover 1984, 1995; Avery 1985). Birds can be conditioned to avoid foods when they learn to associate a visual cue with illness induced by secondary repellents. Moreover, the entire crop does not require treatment (Avery 1985), and not all birds need to ingest treated foods because birds that observe toxicosis among cohorts will also learn to avoid foods they associate with visual cues (Mason and Reidinger 1982, 1983b; Mason 1987).

A third advantage of primary repellents is that environmental safety and registration may not be as much of a concern as with secondary repellents, especially if physiologically and environmentally benign repellents are used. Many candidate primary repellents are from natural plant products that have already received approval as food additives (Mason and Clark 1987, Clark et al. 1991, Avery et al. 1996). Information on toxicity already exists for these compounds, and such knowledge could help expedite the registration process for repellents (Clark 1998).

Converting primary repellents to secondary repellents appears to hold promise as a tool to reduce avian crop depredation, but additional work is needed before this becomes feasible. Most importantly, the animals need to ingest sufficient quantities of the chemicals so that food aversion learning is induced. A major hurdle is to establish methods that mask these repellents so the peripheral senses are bypassed. However, the masking must not compromise the formulation or efficacy of the compound.

The use of primary repellents to reduce avian depredation has potential. By integrating basic ecological and behavioral paradigms with existing knowledge on chemical properties and physiological effects, wildlife managers can develop options that are effective, safe, and nonlethal.

\section{ACKNOWLEDGMENTS}

This study was supported by USDA/APHIS Wildlife Services Chemical Repellents Project and by the APHIS Postdoctoral Fellows program. We thank M. E. Tobin and 2 anonymous referees 
for review and comments of the manuscript. We appreciate K. Dyer, J. Saylor, M. Parks, and K. Patz for their assistance with video analysis.

\section{LITERATURE CITED}

Aronov, E. V., AND L. Clark. 1996. Degradation studies of the non-lethal bird repellent, methyl anthranilate. Pesticide Science 47:355-362.

AVERY, M. L. 1985. Application of mimicry theory to bird damage control. Journal of Wildlife Management 49:1116-1121.

- T. M. Primus, J. Defrancesco, J. L. Cummings, D. G. Decker, J. S. Humphrey, J. E. Davis, AND R. DeACON. 1996. Field evaluation of methyl anthranilate for deterring birds eating blueberries. Journal of Wildlife Management 60:929-934.

Clark, L. 1996. Trigeminal repellents do not promote conditioned odor avoidance in European starlings. Wilson Bulletin 108:36-52.

—. 1998. Physiological, ecological, and evolutionary bases for the avoidance of chemical irritants by birds. Current Ornithology 14:1-37.

—, AND J. R. MASON. 1993. Interaction between sensory and postingestinal repellents in starlings: methyl anthranilate and sucrose. Ecological Applications 3:262-270.

— - AND P. S. SHAH. 1991. Chemical repellency in birds: relationship between chemical structure and avoidance response. Journal of Experimental Zoology 260:310-322.

CONOVER, M. R. 1984. Response of birds to different types of food repellents. Journal of Applied Ecology 21:437-443.

- 1995. Behavioral principles governing conditioned food aversions based on deception. Pages 29-41 in J. R. Mason, editor. Repellents in wildlife management: proceedings of a symposium. National Wildlife Research Center, Fort Collins, Colorado, USA. Dolbeer, R. A., M. L. Avery, AND M. E. Tobin. 1994. Assessment of field hazards to birds from methiocarb applications to fruit crops. Pesticide Science 40:147-161.

DOMJAN, M. 1998. The principles of learning and behavior. Fourth edition. Brooks/Cole, Pacific Grove, California, USA.

FAgerstone, K. A., AND E. W. Schafer, JR. 1998. Status of APHIS vertebrate pesticides and drugs. Proceedings of the Vertebrate Pest Conference 18:319-324.

Garcia, J. R., R. Kovner, AND K. F. Green. 1966. Cue properties vs. palatability of flavors in avoidance learning. Psychonomic Science 20:313-314.

Glahn, J. F., J. R. Mason, AND D. R. Woods. 1989. Dimethyl anthranilate as a bird repellent in livestock feed. Wildlife Society Bulletin 17:313-320.

MARTIN, P., AND P. BATESON. 1993. Measuring behaviour. Second edition. Cambridge University Press, Cambridge, United Kingdom.
MASON, J. R. 1987. Direct and observational learning by redwinged blackbirds (Agelaius phoeniceus): the importance of complex visual stimuli. Pages 99-115 in T. R. Zentall and B. G. Galef, editors. Social learning: psychological and biological perspectives. Lawrence Erlbaum Associates, Hilldale, New Jersey, USA.

- A. H. ARZT, AND R. F. ReIdinger. 1984. Comparative assessment of food preferences and aversions acquired by blackbirds via observational learning. Auk 101:796-803.

- AND L. CLARK. 1987. Dimethyl anthranilate repellency to reduce grazing by Canada geese (Branta canadensis). Denver Wildlife Research Center Report 38:1-11.

- AND — 1992. Nonlethal repellents: the development of cost-effective, practical solutions to agricultural and industrial problems. Proceedings of the Vertebrate Pest Conference 15:115-129.

, AND R. F. REIDINGER. 1982. Observational learning of food aversions in red-winged blackbirds. Auk 99:548-554.

$\longrightarrow$, AND —. 1983a. Importance of color for methiocarb-induced food aversions in red-winged blackbirds. Journal of Wildlife Management 47:383-393.

— AND —. 1983b. Conspecific individual recognition between starlings after toxicant-induced sickness. Animal Learning and Behavior 11:332-336.

Nelms, C. O., AND M. L. Avery. 1997. Reducing bird repellent application rates by the addition of sensory stimuli. International Journal of Pest Management 43:187-190.

Pavlov, I. P. 1906. Conditioned reflex. Oxford University Press, Oxford, United Kingdom.

Pelchat, M. L., H. J. Grill, P. Rozin, and J. Jacobs. 1983. Quality of acquired responses to tastes by Rattus norvegicus depends on type of associated discomfort. Journal of Comparative Psychology 97:140-153.

Rogers, J. G., JR. 1974. Responses of caged red-winged blackbirds to two types of repellents. Journal of Wildlife Management 38:418-423.

Sayre, R. W., and L. Clark. 2001. Comparison of primary and secondary repellents for aversive conditioning of European starlings. Pages 324-344 in J. J. Johnston, editor. Pesticides and wildlife. American Chemical Society Series 771. Oxford University Press, Washington, D.C., USA.

SOKAL, R. R., AND F. J. RoHLF. 1984. Biometry: the principles and practice of statistics in biological research. Second edition. W. H. Freeman and Company, New York, USA.

ToBIN, M. E. 1985. Cues used by European starlings for detecting methiocarb-treated grapes. Journal of Wildlife Management 49:1102-1108.

Received 1 December 1999.

Accepted 6 February 2001.

Associate Editor: Giuliano. 